ordnenden Zusammenfassungen, ein geeignetes Einführungsbuch in die Probleme der internationalen Mediendiskussion. Es erleichtert das Verständnis auch durch die "anpakkende", konkrete Ausdrucksweise.

Will Teichert

Egbert Jahn/Yoshikazu Sakamoto (Hg.)

Elements of World Instability: Armament, Communication, Food

International Division of Labour

Campus Verlag, Frankfurt/New York, 1981, 392 S., DM 40,-

Der von Jahn und Sakamoto herausgegebene Sammelband enthält ausgewählte Beiträge der 8. Weltkonferenz der International Peace Research Association, die im August 1979 in Königstein/Taunus stattfand. In dem Buch sind 27 von insgesamt 90 Beiträgen nach thematischen Gesichtspunkten zusammengefaßt; auf diese Weise werden weite Bereiche der internationalen Friedens- und Konfliktforschung abgedeckt.

Gegenstand der Betrachtung sind sowohl die politische Okonomie der Ernährung, die sozialen Auswirkungen der neuen internationalen Arbeitsteilung, die Weltmilitärordnung, das Spannungsfeld von Konflikt und Kooperation im Ost-West-Verhältnis in Europa als auch die Problematik der Friedenserziehung und - als ein relativ neuer Untersuchungsbereich - die Weltinformationsordnung.

Aufgrund der in vielen Regionen und Ländern der Dritten Welt besonders ausgeprägten Instabilität ist es nur folgerichtig, daß den Entwicklungsländern breiter Raum gewidmet wird. Die zahlreichen Konfliktherde und Kriege im sogenannten Süden - in den letzten Monaten und Jahren mit der Konfrontation Irak-Iran als einer der blutigsten und brutalsten Auseinandersetzungen - bedeuten schließlich auch eine reale, wenngleich nicht selten verkannte Gefahr für den Weltfrieden. Es ist so unwahrscheinlich nicht, daß sich ein unkontrolliert ausufernder, mit Waffen des Nordens geführter Regionalkrieg zum Dritten Weltkrieg auswächst.

Mit der Weltwirtschaftsordnung, der Weltinformationsordnung, der Weltmilitärordnung und der Welt-"Ernährungsordnung" sind zudem zentrale Bereiche des Nord-SüdKonflikts angesprochen, aus denen sich langfristig mindestens genausoviel Sprengstoff für den Weltfrieden herleitet wie aus dem Ost-West-Konflikt. Der vielzitierte Nord-SüdDialog existiert weitgehend nur als Phantom; der Norden ist aufgrund seiner ökonomischen und politisch-militärischen Stärke immer noch in der Lage, dem Süden einen Monolog aufzuzwingen: die Bedingungen und das Funktionieren der Weltwirtschafts-, der Weltinformations-, der Weltmilitär- und der Welt-"Ernährungsordnung" werden in hohem Maße von den Schaltzentralen des Nordens diktiert.

In friedenspolitischer Hinsicht bedeutsam erscheint der sechste Teil, der sich dem Thema Friedenserziehung verschreibt, sowie der Aufsatz von Sakamoto und Falk, in dem 
von dem Grundbedürfnis "demilitarisierte Welt" die Rede ist. Neben eher analytischen finden sich somit auch programmatisch orientierte Texte, denen im Rahmen einer praktischen Zielen dienenden Friedens- und Konfliktforschung besondere Beachtung geschenkt werden sollte. Gerade hier bewegt man sich auf einem Terrain, wo sich wohl ein Problemhorizont abstecken läßt, aber noch wenig mit fertigen Lösungen gearbeitet werden kann. Diskussion ist in diesem Bereich um so mehr erforderlich.

Obwohl der Sammelband ein breites Spektrum der internationalen Friedensforschung repräsentiert, sind dennoch gewichtige Mängel zu beklagen: Die Aspekte der internationalen Organisationen und der internationalen Währungs- und Finanzordnung finden keine bzw. kaum Berücksichtigung. Der Aufsatz über die Auslandsverschuldung Lateinamerikas von Herrera - im ersten Teil über die politische Okonomie der Ernährung ohnehin etwas deplaziert wirkend - deckt nur ungenügend einen Bereich ab, der sich in den 70er und frühen 80er Jahren immer mehr zu einem Konfliktpunkt ersten Ranges zwischen Industrieländern und Entwicklungsländern entwickelt hat. Es hätte dieses wichtige und in seiner thematischen Auffächerung an sich positiv zu bewertende Buch nicht unwesentlich bereichert, wenn etwa die Tätigkeit von UN, Weltbank, IWF, FAO und anderen Organisationen, die Problematik der internationalen Währungs- und Finanzbeziehungen mit dem Schuldner-Gläubiger-Konflikt oder z. B. die Seerechtskonferenzen über Souveränitätsansprüche auf den Weltmeeren als "Elemente der Weltinstabilität" gründlicher in die Betrachtung eingeschlossen worden wären.

Peter Körner

\section{Menschenrechte und Menschenbild in der Dritten Welt}

Arbeitskreis Dritte Welt und Studium Generale der Johannes Gutenberg-Universität Mainz, Ringvorlesung Wintersemester 1978/79, Verlag Klaus Dieter Vervuert, Frankfurt a. M., 1982, 137 S., DM 12,80

Das Bändchen bietet nützliches, in leicht verständlichen Vorträgen dargebotenes Material zur Rolle der Menschenrechte in Entwicklungsländern. Trotz des erkennbaren Bestrebens, auch ein nicht fachwissenschaftlich vorgebildetes Publikum zu erreichen, erliegen die Autoren nicht der Gefahr der Oberflächlichkeit. Ein gewisser Akzent liegt auf den aktuellen Entwicklungen in Afrika (Ansprenger, Grohs), während Lateinamerika eher historisch (Janik) und im Zusammenhang mit der Außenpolitik Präsident Carters (Mols) betrachtet wird.

Instruktiv sind die Bemerkungen Kohlers zur Situation in Asien, die noch viel zu wenig untersucht ist. Grundsätzlich der Entwicklungsproblematik und ihren Implikationen für den Menschenrechtsschutz sind Beiträge von Thimm und Emil Küng gewidmet, während Schweitzer den völkerrechtlichen Rahmen, der der Menschenrechtspolitik der Entwicklungsländer gesteckt ist, präzise nachzeichnet. Das Buch bietet ein gelungenes Bei- 